\title{
Right Submandibular Gland Aplasia with Contralateral Submandibular Gland Hypertrophy
}

\author{
Dr. Syedha Fariheen Fathimah $\mathrm{M}^{1}$, Dr. R. Monika ${ }^{2 *}$, Dr. Kalaichezhian Mariappan ${ }^{3}$, Dr. Prabakaran $\mathrm{M}^{4}$
}

${ }^{1}$ Post Graduate Resident, Department of Radio-diagnosis, Sree Balaji Medical College and Hospital, 7 Works Road, Chromepet, Chennai, Tamilnadu, India

${ }^{2}$ Post Graduate Resident, Department of Radio-diagnosis Sree Balaji Medical College and Hospital 7 Works Road, Chromepet Chennai, Tamilnadu, India

${ }^{3}$ Consultant, Department of Radio-diagnosis Sree Balaji Medical College and Hospital 7 Works Road, Chromepet Chennai, Tamilnadu, India

${ }^{4}$ Head of Department, Department of Radio-diagnosis Sree Balaji Medical College and Hospital 7 Works Road, Chromepet Chennai, Tamilnadu, India

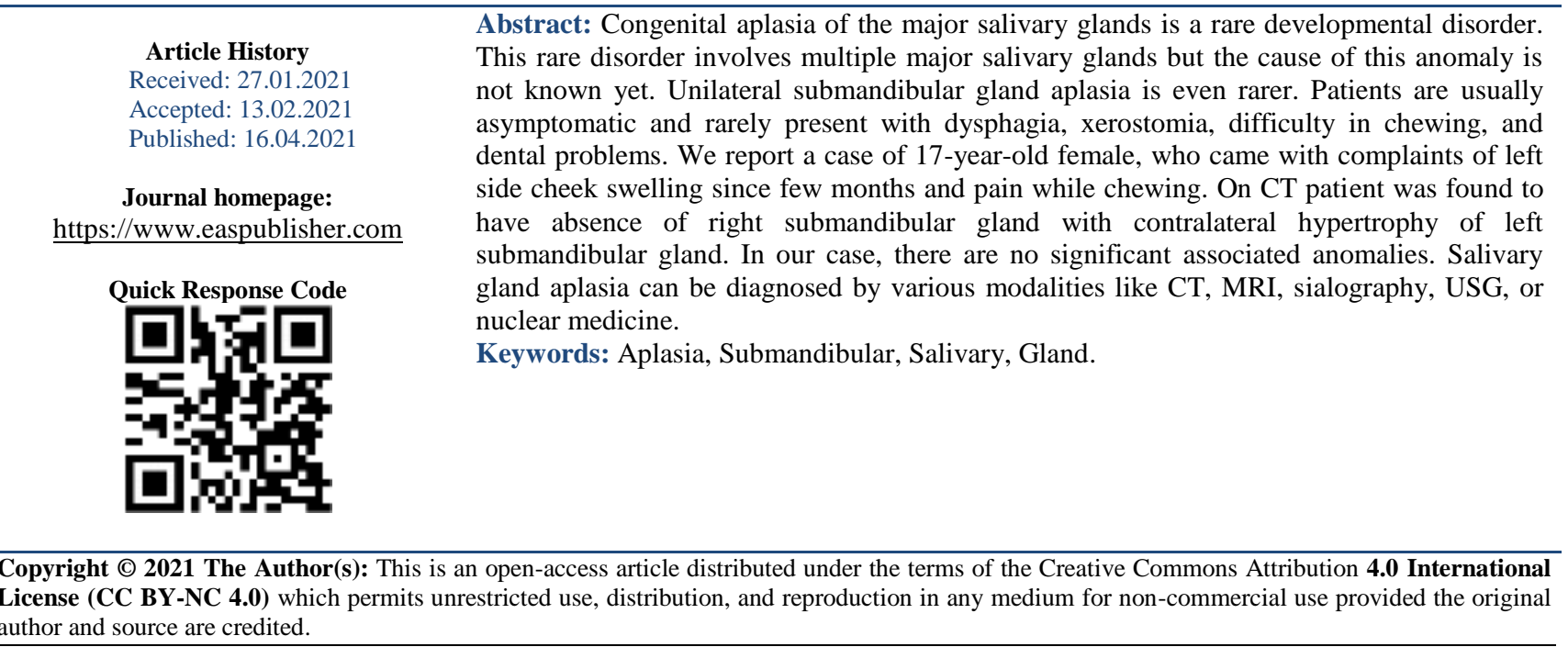

\section{INTRODUCTION}

Congenital absence of the salivary glands is not a frequent disorder, which is known to involve parotid and submandibular gland. Aplasia of major salivary gland is often associated with facial developmental anomalies [1, 2]. Patients with salivary gland aplasia are often asymptomatic, but may present with xerostomia, dysphagia, and difficulty in chewing and dental abnormalities [3, 4]. The term "aplasia" is described as the total or partial agenesis of the gland .Approximately 40 cases were reported in the medical literature. The first case was presented in 1885 by Gruber and was a bilateral submandibular aplasia [5]. The reason for isolated aplasia of submandibular salivary gland is not yet known, as most of the reported cases occur along with other developmental anomalies of the face such as hemifacial microsomia, lacrimo-auricular-dento-digital syndrome, and mandibulofacial dysostosis [6]. We report a case of incidentally detected unilateral submandibular gland aplasia, with ipsilateral sublingual gland hypertrophy mimicking a mass, demonstrated on CT. The first reported case and was a bilateral submandibular gland aplasia and was presented by Gruber in 1885[4].

\section{Case Report}

A 17 year old female, came with complaints of left sided cheek swelling since few months and pain while chewing. On Clinical examination, patient had palpable, swelling on the left cheek, otherwise examination of the oral cavity and oropharynx did not show any palpable masses, lymphadenopathy, and indirect laryngoscopy showed a normal larynx with mobile cords and a clear base of the tongue. Patient was referred to radiology department for CT evaluation. CT showed absence of right submandibular gland, and enlargement of left submandibular gland. Bilateral parotid glands were of normal size, and no other specific salivary gland enlargement was detected. The patient was evaluated further. She did not give any 
history such as dry mouth, dysphagia, teeth and gum problems, or sialadenitis and had no significant family history. There was no previous history of head and neck surgery or known malignancy. Patient's lack of history of salivary gland related symptoms was probably due to the unilateral nature of the aplasia, with the other major salivary glands being present and compensatory hypertrophy of the ipsilateral submandibular gland. In our patient, we were able to confirm the diagnosis of compensatory submandibular gland hypertrophy by using a combination of CT and MR imaging, including dynamic contrast-enhanced sequences. The imaging findings confirmed the absence of the right submandibular gland with associated hypertrophied contralateral submandibular gland.

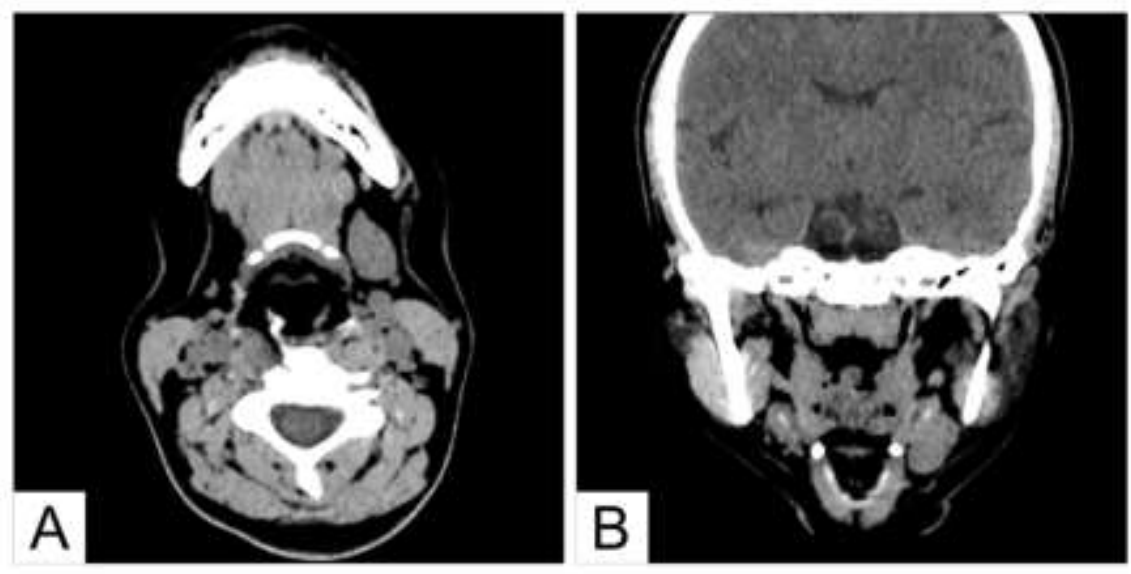

Legend: CT neck Axial (A) and coronal (B) sections show absence of right submandibular salivary gland and contralateral hypertrophy of left submandibular salivary gland

\section{DISCUSSION}

Ectodermal defects of the first and second branchial arches is known to be cause of Agenesis of major salivary glands, lacrimal punctum aplasia or hypoplasia and agenesis of lacrimal glands [7]. From the lining of oral epithelial lining, the salivary glands originate as buds. Further these primordial buds extend into their respective mesenchymal tissue as solid core of cells. This tissue in turn develops into branching tissue and lumina. The surrounding mesenchymal tissue divides them in to lobules and covers them as capsule. Major salivary glands like parotid glands starts developing at fourth week of gestation, submandibular glands at sixth week, and the sublingual glands during the ninth week of gestation [6]. Congenital aplasia of the salivary glands are not a very common scenario if present more often involves multiple major salivary glands. Most common salivary gland involved in aplasia is parotid gland followed by submandibular gland. Out of 40 cases of unilateral major salivary gland aplasia, Unilateral Isolated submandibular salivary gland aplasia is rarest among which Nonfamilial presentation is again very infrequent among the unilateral isolated submandibular aplasia [8].

There is a compensatory enlargement of contralateral major or accessory salivary gland which usually present as clinical and radiological pseudo masses as in our case where left submandibular gland is found to be enlarged [6]. Unilateral or bilateral salivary gland aplasia may be associated with other abnormalities like the first and second branchial arch abnormalities, Genetic syndromes such as Treacher-
Collins syndrome, hemifacial microsomia, ectodermal dysplasia, and lacrimo auriculo-dento-digital syndrome[10].

Patients with salivary gland aplasia presents with xerostomia, recurrent dental infections, sialadenitis, dysphagia, difficulty in chewing and oropharyngeal inflammation. In these patients further evaluation has to be done to look for major glandular duct orifices, sialometry for salivary flow and Schirmer's test to quantitate lacrimation. Absence of activity of aplastic salivary gland can be evaluated using salivary gland scintigraphy [9]. Salivary gland aplasia can be diagnosed with a variety of imaging techniques, which include CT, MR imaging, sonography, sialography, or nuclear medicine studies $[1,2,4,6,13-15]$. However, without the help of intravenous contrast, plain soft-tissue CTof the neck is seen to provide a definitive diagnosis due to its easy accessibility, speed, acceptable soft-tissue contrast and multiplanar capability by virtue of multidetector CT (MDCT) technology [9].

Differential diagnosis of the salivary gland can be classified as malignant or non-malignant growth. Non-malignant growths include sialadenitis, Sjogren syndrome, cysts, infection and lymphadenopathy. Malignant growths such as SMG, the tail parotid gland, the Hodgkin's disease, non-Hodgkin's lymphomas, and metastatic disease may be seen [10]. Other causes of aplasia of salivary gland is seen as a part of lacrimoauriculodentodigital syndrome, where hypoplasia, aplasia or atresia of the lacrimal system, 
deafness and ear malformations, and dental and digital anomalies[11].

\section{CONCLUSION}

Unilateral submandibular gland aplasia is rarest among unilateral non familial salivary gland aplasia. Since unilateral aplasia of submandibular gland is mostly asymptomatic and present incidentally, there is no information about the incidence. Associated hypertrophy of contralateral glands or accessory salivary tissue should be included in the differential of palpable masses. The patient's symptoms should be subjected for evaluation to rule out other associated defects and abnormalities. Radiologist should be well aware of this condition to rule out malignant swellings and to avoid unnecessary intervention.

\section{REFERENCES}

1. McDonald, F. G., Mantas, J., McEwen, C. G., \& Ferguson, M. M. (1986). Salivary gland aplasia: an ectodermal disorder?. Journal of Oral Pathology \& Medicine, 15(2), 115-117.

2. Higashino, H., Horii, T., Ohkusa, Y., Ohkuma, H., Ino, C., Nakazawa, M., ... \& Kobayashi, Y. (1987). Congenital absence of lacrimal puncta and of all major salivary glands: case report and literature review. Clinical pediatrics, 26(7), 366-368.

3. Whyte, A. M., \& Hayward, M. W. J. (1989). Agenesis of the salivary glands: a report of two cases. The British journal of radiology, 62(743), 1023-1026.

4. Yılmaz, M., Yücel, A., Dereköy, S., \& Altuntaş, A. (2002). Unilateral aplasia of the submandibular gland. European Archives of Oto-RhinoLaryngology, 259(10), 554-556.

5. Yilmaz, M., Yücel, A., Dereköy, S., \& Altuntaş, A. (2002). Unilateral aplasia of the submandibular gland. European Archives of Oto-RhinoLaryngology, 259(10), 554-556.

6. Yılmaz, M., Yücel, A., Dereköy, S., \& Altuntaş, A. (2002). Unilateral aplasia of the submandibular gland. European Archives of Oto-RhinoLaryngology, 259(10), 554-556.
7. Srinivasan, A., Moyer, J. S., \& Mukherji, S. K. (2006). Unilateral submandibular gland aplasia associated with ipsilateral sublingual gland hypertrophy. American Journal of Neuroradiology, 27(10), 2214-2216.

8. Fracaro, M. S., Linnett, V. M., Hallett, K. B., \& Savage, N. W. (2002). Submandibular gland aplasia and progressive dental caries: a case report. Australian dental journal, 47(4), 347-350.

9. Dhiman, N. K., Vishwakarma, A. K., Verma, V., \& Singh, S. (2018). Nonfamilial unilateral aplasia of the submandibular gland: A rare finding. Journal of Oral and Maxillofacial Radiology, 6(1), 14.

10. Ahmed, M., Strauss, M., Kassaie, A., Shotelersuk, V., \& DeGuzman, R. (2009). Bilateral submandibular gland aplasia with clinicoradiological mass due to prolapsing sublingual salivary tissue through mylohyoid boutonniere: a case report and review. Dentomaxillofacial Radiology, 38(2), 121-124.

11. Kara, M., Güçlü, O., Dereköy, F. S., Resorlu, M., \& Adam, G. (2014). Agenesis of submandibular glands: a report of two cases with review of literature. Case reports in otolaryngology, 2014.

12. Hollister, D. W., Klein, S. H., De Jager, H. J., Lachman, R. S., \& Rimoin, D. L. (1973). The lacrimo-auriculo-dento-digital syndrome. The Journal of pediatrics, 83(3), 438-444.

13. Smith, N. J. D., \& NJD, S. (1977). Congenital absence of major salivary glands.

14. Sucupira, M. S., Weinreb, J. W., Camargo, E. E., \& Wagner, H. N. (1983). Salivary gland imaging and radionuclide dacryocystography in agenesis of salivary glands. Archives of Otolaryngology, 109(3), 197-198.

15. Myers, M. A., Youngberg, R. A., \& Bauman, J. M. (1994). Congenital absence of the major salivary glands and impaired lacrimal secretion in a child: case report. Journal of the American Dental Association (1939), 125(2), 210-212.

16. Yoshiura, K., Yamada, M., \& Yamada, N. (1990). Demonstration of congenital absence of the major salivary glands by computed tomography. Dentomaxillofacial Radiology, 19(2), 77-78.

Cite This Article: Syedha Fariheen Fathimah M et al (2021). Right Submandibular Gland Aplasia with Contralateral Submandibular Gland Hypertrophy. EAS J Radiol Imaging Technol, 3(2), 66-68. 